\title{
Validation of Responsiveness of Physicians Scale (ROP-Scale) for Hospitalized COVID-19 Patients in Bangladesh
}

Taufique Joarder ( $\nabla$ taufiquejoarder@gmail.com )

Public Health Foundation, Bangladesh

Mohammad Aminul Islam

University of Liberal Arts Bangladesh

Md Shariful Islam

Public Health Foundation, Bangladesh

Shabnam Mostari

Aspire to Innovate Programme, ICT Division, Government of Bangladesh

Md. Tanvir Hasan

BRAC University

\section{Research Article}

Keywords: Responsiveness of physicians, patient satisfaction, psychometric evaluation, scale validation, Bangladesh

Posted Date: October 1st, 2021

DOI: https://doi.org/10.21203/rs.3.rs-891639/v1

License: (c) (i) This work is licensed under a Creative Commons Attribution 4.0 International License. Read Full License 


\section{Abstract}

\section{Background}

Responsiveness of Physicians (ROP) is defined as the social actions by physicians aimed at meeting the legitimate expectations of healthcare users. Even though patients' expectations regarding ROP have increased during the COVID-19 pandemic, the psychometrically-validated ROP-Scale is difficult to apply in hospital settings. The goal of this study is to validate the existing ROP-Scale to measure the responsiveness of hospital physicians during the ongoing COVID-19 pandemic in Bangladesh.

\section{Methods}

We conducted a cross-sectional phone survey involving 213 COVID-19 hospital patients, randomly selected from the government database. We applied the Delphi method for content validity, exploratory factor analysis for construct validity, Cronbach's alpha and corrected item-total correlation for internal consistency reliability, and Pearson's correlation between the scale and overall patient satisfaction for concurrent validity.

\section{Results}

After removing survey items based on data sufficiency, collinearity, factor loading, and internal consistency, the final version of the COVID-19 ROP-Scale consisted of 12 items, grouped under Courteousness, Informativeness, Financial Sensitivity, and Treatment Provision Sensitivity domains. The scale was internally consistent, with a Cronbach's alpha coefficient of 0.83 . The corrected item-total correlation ranged between 0.37 and 0.72 . Concurrent validity was ascertained by the high correlation (0.78) between patient satisfaction and the COVID-19 ROP-Scale. Based on the median domain score, the highest- and the lowest-scoring responsiveness domain was 'Courteousness' (7.45) and 'Financial sensitivity' (1.85), respectively, whereas the highest- and the lowest-scoring item was 'Respect during the consultation' (8.16), and 'Providing treatment cost estimate before starting treatment' (1.78).

\section{Conclusions}

The 12-item COVID-19 ROP-Scale was demonstrated to be feasible, valid, and internally consistent. Therefore, at a time when many countries, including Bangladesh, have started experiencing new pandemic waves, its application can help amend past mistakes in health service provision and improve care for the hospitalised COVID-19 patients or other patients suffering from similar conditions. This study can contribute to the national decision-making regarding hospital care, open up further avenues in the health policy and system research, and eventually improve the quality of care provided to Bangladeshi patients seeking hospital services. Moreover, findings yielded by this study can be incorporated into doctors' medical education and in-service training.

\section{Introduction}


The aim of health systems is delivering patient care in a timely manner. To this end, Responsiveness of Physicians (ROP) refers to the social actions by physicians to meet the legitimate expectations of healthcare users $(1,2)$. This is particularly important in a pandemic situation when patient load is high, and physicians are strained both physically and mentally (3). Failure to respond to patent needs is associated with hesitation to follow-up (4) and even treatment discontinuation (5).

The ongoing COVID-19 pandemic has brought multiple challenges for both healthcare providers and patients, as it has increased anxiety, distrust, and uncertainty $(6,7)$, necessitating greater sensitivity to patient needs. As a result, ROP has gained attention of both policymakers and scholars from various disciplines such as public health, social psychology, social medicine, healthcare communication, and media studies.

Yet, measuring ROP in times of crises can be challenging, necessitating a reliable and objective scale pertaining to different aspects of physicians' responsiveness and help them mend the gaps and improve their performance. During the pandemic, various disturbing allegations have been made against the physicians by COVID-19 patients in many low- and middle-income countries, including Bangladesh, ranging from medical negligence to outright denial to provide medical services. By providing physicians with an evidence-based set of activities or behaviours during the consultation process, they would be better prepared to care for patients suffering from COVID-19, thus improving public trust in healthcare services (7).

Although a psychometrically-validated ROP-Scale with five sub-scales and 34 items characterised by high internal consistency (alpha coefficient of 0.91) and inter-rater reliability (Intraclass Correlation Coefficient of 0.64 for individual rater's reliability and 0.84 for average reliability scores) exists (8), it not only requires structured observation but was developed in the rural outpatient context of Bangladesh. Thus, it was not intended for hospital settings or times of infectious disease outbreaks. As most COVID-19 patients receive care from the inpatient department of a hospital or clinic and require appropriate care and observation, the ROP-Scale needs to be validated for this setting. Thus, as a part of the present study, the existing ROP-Scale was validated using psychometric techniques to measure the responsiveness of inpatient hospital physicians during the ongoing COVID-19 pandemic in Bangladesh.

\section{Methods}

\section{Design:}

The data gathered via a cross-sectional phone survey involving 213 persons who received COVID-19 care in July 2020 from any COVID-19-specific hospital designated by the Government of Bangladesh (GoB) were subjected to psychometric analyses to validate the existing ROP-Scale (8).

\section{Participants:}


The study participants were recruited from both public and private COVID-19 designated hospitals across Bangladesh and were identified through the database of COVID-19 patients provided by the Aspire to Innovate (A2i) Programme, Information and Communication Technology (ICT) Division of the GoB that contains patient's name, disease outcome, date of admission and discharge, hospital name, and contact information. We sampled potential respondents from the database and extracted the contact information for the survey which was conducted over the phone due to the pandemic.

Only adult patients (aged $\geq 18$ years) who were treated in one of the COVID-19 dedicated hospitals in July 2020 whose correct phone number was available in the database were eligible for participation. Those that did not consent to participate or could not be reached after calling three times at different time points were excluded from the sample.

\section{Content validity:}

Item clarity and content validity were established using a modified Delphi technique. The first author, who is a health policy and systems researcher with expertise in psychometrics, served as the facilitator. $\mathrm{He}$ convened the panel of experts (all of whom are the article co-authors) comprising of two public health physicians, a communication expert, and a biostatistician experienced in psychometrics, and provided them with the existing ROP-Scale, along with the guidelines for refining its 34 items through three iterations. The aim was to ensure that the scale items are (1) comprehendible over the phone, (2) applicable to the COVID-19 inpatient hospital context, and (3) appropriate for a questionnaire survey (the original ROP-Scale items were designed for structured observation and the five response categories were anchored in an outpatient consultation scenario), and that (4) the whole questionnaire is short enough not to discourage voluntary participation.

\section{Sample size and sampling techniques:}

The sample size was determined based on the $10: 1$ " $n$ to $p$ ratio" $(9,10)$, where ' $n$ ' is the minimum sample size, and ' $p$ ' is the number of items. Since the initial tool consisted of 20 items, the required sample size was 200 . Anticipating a $20 \%$ non-response rate, as the survey was to be conducted over the phone and the patients may be weak and reluctant to participate after recovering from COVID-19, we approached 250 patients and obtained 213 valid responses. We used the RAND function in MS Excel (MS Office Professional Plus 2016) to randomly select the 250 patients based on simple random sampling technique.

\section{Data collection instruments and procedures:}

The survey questionnaire consisted of two parts: (1) Socio-demographic characteristics (age, gender, education, occupation, current residence, religion, marital status, and monthly income), and (2) ROP-Scale items. From the database, we also extracted the location and type of hospitals (public or private) in which the patients received care, duration of hospital stay, and disease severity. The ROP-Scale section was further subdivided into seven sub-sections, namely (1) Beginning part, (2) History taking, (3) Examination, 
(4) Prescribing, (5) Explaining, (6) Leaving, and (7) Throughout consultation. Respondents were also asked to rate their level of overall satisfaction with the services received from the doctors in the hospital. The 20-item draft tool was pilot-tested on five non-sampled patients and the language was improved for intelligibility based on their feedback. The original ROP-Scale items and the draft COVID-19 ROP-Scale items used for data collection in this research are shown in Table 1.

\section{Table 1: ROP-Scale's original items and draft items for this study}




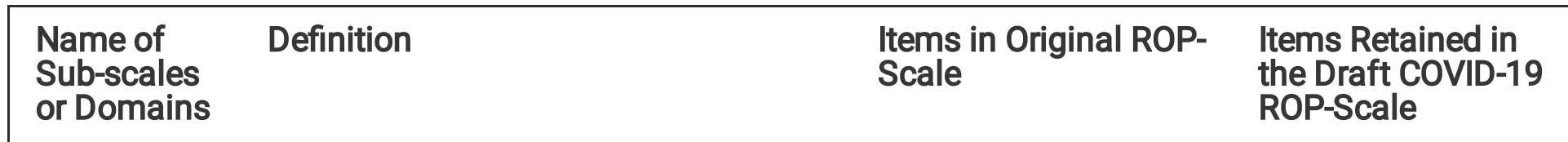

Friendliness How a physician communicates with a patient

1. Asking patient's name

1. Engaging in social talks

2. Engaging in social talks

3. Asking about patient's family

2. Friendliness

3. Giving courage and

4. Friendliness

5. Giving courage reassurance and reassurance

4. Sense of

6. Sense of humour

Respecting How a physician explicitly shows respect to a patient

1. Greetings by physician

2. Showing respect explicitly

3. Listening to patient's complaints completely

4. Listening to patient's complaints attentively

5. Examining the patient with care

6. Encouraging patient to ask questions

7. Listening attentively to patient's questions

8. Closing salutation by physician

9. Non-verbal communication by physician

10. Compassionately touching the patient by physician

Informing How a physician empowers a patient and guiding
1. Suggestions on disease prevention and health promotion in general
1. Greetings by physician

2. Showing respect explicitly

3. Listening to patient's complaints attentively

4. Examining the patient with care

5. Encouraging patient to ask questions 


\begin{tabular}{|c|c|c|c|}
\hline & & $\begin{array}{l}\text { 2. Facilitating } \\
\text { follow-up } \\
\text { 3. Quantity of } \\
\text { issues explained } \\
\text { and the quality } \\
\text { of explanation } \\
\text { 4. Quantity of } \\
\text { issues explained } \\
\text { 5. Asking patient if } \\
\text { s/he understood } \\
\text { the explanation } \\
\text { 6. Explaining the } \\
\text { cause of disease } \\
\text { to the patient } \\
\text { 7. Explaining the } \\
\text { diagnosis of } \\
\text { disease to the } \\
\text { patient } \\
\text { 8. Explaining the } \\
\text { prognosis of } \\
\text { disease to the } \\
\text { patient } \\
\text { 9. Explaining the } \\
\text { treatment to the } \\
\text { patient } \\
\text { 10. Explaining the } \\
\text { preventive } \\
\text { aspects to the } \\
\text { patient }\end{array}$ & $\begin{array}{l}\text { disease to the } \\
\text { patient } \\
\text { 3. Explaining the } \\
\text { diagnosis of } \\
\text { disease to the } \\
\text { patient } \\
\text { 4. Explaining the } \\
\text { prognosis of } \\
\text { disease to the } \\
\text { patient } \\
\text { 5. Explaining the } \\
\text { treatment to } \\
\text { the patient } \\
\text { 6. Explaining the } \\
\text { preventive } \\
\text { aspects to the } \\
\text { patient }\end{array}$ \\
\hline $\begin{array}{l}\text { Gaining } \\
\text { trust }\end{array}$ & $\begin{array}{l}\text { How a physician may gain trust of } \\
\text { the patients, or refrains from doing } \\
\text { something that may breach trust of } \\
\text { the patients }\end{array}$ & $\begin{array}{l}\text { 1. Earning trust of } \\
\text { patients } \\
\text { 2. Service oriented, } \\
\text { not business-like } \\
\text { attitude } \\
\text { 3. Not using jargon } \\
\text { 4. Not being } \\
\text { involved in illegal } \\
\text { activities }\end{array}$ & $\begin{array}{l}\text { 1. Service } \\
\text { oriented, not } \\
\text { business-like } \\
\text { attitude } \\
\text { 2. Not being } \\
\text { involved in } \\
\text { illegal activities }\end{array}$ \\
\hline $\begin{array}{l}\text { Financial } \\
\text { sensitivity }\end{array}$ & $\begin{array}{l}\text { Understanding financial need of the } \\
\text { patients and providing support if } \\
\text { needed, going beyond the } \\
\text { consultation }\end{array}$ & $\begin{array}{l}\text { 1. Considering the } \\
\text { socio-economic } \\
\text { status of the } \\
\text { patient } \\
\text { 2. Trying to } \\
\text { understand the } \\
\text { socio-economic } \\
\text { status of the } \\
\text { patient } \\
\text { 3. Informing the } \\
\text { cost of } \\
\text { treatment } \\
\text { 4. Providing } \\
\text { financial }\end{array}$ & $\begin{array}{l}\text { 1. Trying to } \\
\text { understand the } \\
\text { socio- } \\
\text { economic } \\
\text { status of the } \\
\text { patient } \\
\text { 2. Informing the } \\
\text { cost of } \\
\text { treatment } \\
\text { 3. Providing } \\
\text { financial } \\
\text { assistance if } \\
\text { needed }\end{array}$ \\
\hline
\end{tabular}


A team of masters-level students at the Communication Department of a Bangladeshi university served as data collectors. When contacting each of the respondents randomly chosen from the A2i database, they provided a brief explanation of the study objectives and procedures, as well as voluntary nature of their participation, and ensured them of the anonymity and confidentiality of the information gathered through the survey. After obtaining verbal informed consent from the eligible respondents, the data collectors conducted the interview over the phone, which took 20-30 minutes to complete. The respondents answered the 20 responsiveness questions using a 10-point scale, where 1 indicates negativity and 10 indicates positivity. Thus, a higher score corresponds to greater ROP.

\section{Data management and analysis:}

All data analyses, including data management, cleaning, missing value imputation, calculation of descriptive statistics, and psychometric analysis were conducted using Stata 16 . We performed an exploratory factor analysis (EFA) to measure the factor structure and psychometric properties of the initial COVID-19 ROP-Scale comprising of 20 items. As only 53 and 36 respondents answered the question related to examining patients (item 6) and offering financial assistance if needed (item 9), respectively, these two items were excluded from further analysis. The remaining 18 items were subjected to correlation matrix analysis, which revealed that item 10 (Explaining the cause of the disease to the patient) and item 11 (Explaining the disease diagnosis to the patient) were highly correlated (correlation coefficient value >0.95). Therefore, to avoid the multicollinearity issue, item 10 was excluded, and EFA was performed again on the remaining 17 items. Since some of the values were missing, the maximum likelihood approach with expectation-maximisation (EM) algorithm was used to estimate the covariance matrix (11). The factormat command in Stata was used to obtain the factor solution. Orthogonal varimax option was chosen for factor rotation (12) and Kaiser's criteria (eigenvalue $>1$ rule) were adopted to determine the number of factors to be retained in the model (13). As only items with factor loadings $\geq 0.4$ were retained (14), items 3 (Friendliness of the physician), 5 (Listening to patient's complaints attentively), and 15 (Encouraging patient to ask questions) were excluded. Before EFA, we checked the suitability of data for factor analysis by conducting Bartlett's test and Kaiser-Meyer-Olkin (KMO) test (15).

Cronbach's alpha was used to assess the internal consistency reliability of all the items and all four retained sub-scales or domains. The corrected item-total correlation was also calculated. Factor 4 , with its two items-18 (Service oriented, not business-like attitude) and 19 (Not being involved in illegal activities) -were eliminated at this stage, resulting in 12 items. Concurrent validity of this final version of COVID-19 ROP-Scale was assessed by examining Pearson's correlation between the COVID-19 ROP-Scale score (i.e., the summed score of all item scores) and overall patient satisfaction, under the assumption that responsiveness would be positively correlated with satisfaction $(16,17)$. Figure 1 shows the COVID-19 ROP-Scale validation process. 


\section{Results}

\section{Characteristics of sample:}

As can be seen from Table 2, the mean age and family size of the 213 participants (65\% of whom were male) was 40 years and five members, respectively, and monthly income was 21,000 Bangladeshi Taka (USD 244). The participating patients were hospitalised for nine days on average, and spent about 23,000 Bangladeshi Taka (USD 269) on their care. Majority of the respondents (94\%) received healthcare from a public hospital.

Table 2 Socio-demographic and health service characteristics of the respondents 


\section{Background characteristics}

Mean Standard

Deviation

Age (years)

40.43

14.47

Family members (number)

5.03

1.92

Monthly income (Bangladeshi Taka)

20828.64

21684.87

(USD

244)

Number of days in hospital

9.24

22941.78

(USD

269)

\section{Frequency Percentage}

Gender

Male

Female

Education

Religion

Marital Status

Occupation

No education
Primary complete
Secondary complete (SSC and HSC)
Graduate and above
Islam
Hinduism
Christianity

Currently Married

Separated/ Deserted/ Divorced

Never married

Urban

Rural

Farmer/agricultural worker

Business/ informal worker

Service holder/ government/ private formal job

139

74

6

13

98

96

172

40

1

181

6

26

148

65

5

20

139
65.26

34.74

2.82

6.10

46.01

45.07

80.75

18.78

0.47

84.98

2.82

12.21

69.48

30.52

2.35

9.39

\subsection{6}




\begin{tabular}{|c|c|c|c|}
\hline & Housewife & 19 & 8.92 \\
\hline & Day labourer & 1 & 0.47 \\
\hline & Student & 8 & 3.76 \\
\hline & Retired/ senior citizen & 15 & 7.04 \\
\hline & Unemployed & 5 & 2.35 \\
\hline & Others & 1 & 0.47 \\
\hline \multirow{3}{*}{$\begin{array}{l}\text { Housing type (Number of } \\
\text { rooms) }\end{array}$} & Below 3 & 110 & 51.64 \\
\hline & $3-4$ & 59 & 27.70 \\
\hline & 5 or More & 44 & 20.66 \\
\hline \multirow[t]{2}{*}{ Type of healthcare facility } & Public sector & 201 & 94.37 \\
\hline & Private sector & 12 & 5.63 \\
\hline \multirow[t]{3}{*}{ Severity of illness } & Mild & 119 & 55.87 \\
\hline & Moderate & 72 & 33.80 \\
\hline & Severe & 22 & 10.33 \\
\hline
\end{tabular}

\section{Content validity:}

The expert panel assessed the relevance and phrasing of the 20-item draft COVID-19 ROP-Scale and discussed any changes until reaching a consensus.

\section{Construct validity:}

\section{Determining the number of factors to retain}

The calculated KMO and Bartlett's test was 0.85 with a $p<0.001$. EFA with orthogonal varimax rotation and maximum likelihood method suggested an 11-factor model. However, as per the Kaiser's criteria (eigenvalue $>1$ rule) five factors were considered to be relevant.

\section{Factor extraction and rotation}

In the final factor loading analysis, the items 'Greetings by physician, 'Engaging in social talk,' 'Showing respect explicitly,' and 'Giving courage and reassurance' were loaded heavily (with $0.81,0.83$, 0.60 , and 0.57 loadings, respectively) on Factor 1 . Similarly, items 'Explaining the diagnosis of disease to the patient,' 'Explaining the prognosis of disease to the patient,' 'Explaining the preventive aspects to the patient,' and 'Facilitating follow-up' were loaded heavily (with $0.70,0.45,0.52$, and 0.66 loadings, respectively) on Factor 2 . The items 'Trying to understand the socio-economic status of the patient' and 'Informing the cost of treatment' loaded heavily (with 0.98 and 0.89 loadings, respectively) on 
Factor 3, while the items 'Service-oriented, not business-like attitude' and 'Not being involved in illegal activities' were loaded (with 0.70 and 0.89 loadings, respectively) on Factor 4. Finally, items 'Explaining the treatment to the patient' and 'Sense of humour' were loaded (with 0.74 and 0.88 loadings, respectively) on Factor 5 (Table 3).

\section{Table 3: Rotated pattern matrix of exploratory factor analysis}

\begin{tabular}{|c|c|c|c|c|c|}
\hline Items & $\begin{array}{l}\text { Factor } \\
1\end{array}$ & $\begin{array}{l}\text { Factor } \\
2\end{array}$ & $\begin{array}{l}\text { Factor } \\
3\end{array}$ & $\begin{array}{l}\text { Factor } \\
4\end{array}$ & $\begin{array}{l}\text { Factor } \\
5\end{array}$ \\
\hline Greetings by physician & 0.81 & & & & \\
\hline Engaging in social talks & 0.83 & & & & \\
\hline Showing respect explicitly & 0.60 & & & & \\
\hline $\begin{array}{l}\text { Trying to understand the socio-economic status of } \\
\text { the patient }\end{array}$ & & & 0.98 & & \\
\hline Informing the cost of treatment & & & 0.89 & & \\
\hline Explaining the diagnosis of disease to the patient & & 0.70 & & & \\
\hline Explaining the prognosis of disease to the patient & & 0.45 & & & \\
\hline Explaining the treatment to the patient & & & & & 0.74 \\
\hline Explaining the preventive aspects to the patient & & 0.52 & & & \\
\hline Facilitating follow-up & & 0.66 & & & \\
\hline Giving courage and reassurance & 0.57 & & & & \\
\hline Service-oriented, not business-like attitude & & & & 0.70 & \\
\hline Not being involved in illegal activities & & & & 0.89 & \\
\hline Sense of humour & & & & & 0.88 \\
\hline
\end{tabular}

\section{Internal consistency:}

The internal consistency reliability of all 14 items (based on the Cronbach's alpha coefficient values) was high, with a reliability coefficient of 0.86 . Moreover, subscale reliability analyses revealed that Cronbach's alpha coefficient values for Factor 1, Factor 2, Factor 3, Factor 4, and Factor 5 were 0.87, 0.76, 0.95, 0.59, and 0.78 , respectively. As the fourth factor had poor internal consistency (only 0.59 ) it was considered unacceptable.

The final COVID-19 ROP-Scale included four factors, i.e., Courteousness, Informativeness, Financial Sensitivity, and Treatment Provision Sensitivity (as shown in Table 4) and had 0.83 Cronbach's alpha coefficient. The corrected item-total correlation ranged between 0.37 and 0.72 . The Pearson's correlation 
coefficient for the level of overall satisfaction and the responsiveness of the COVID-19 ROP-Scale score was 0.78 , which was statistically significant at $5 \%$ level (2-tailed).

Table 4: The COVID-19 Responsiveness of Physicians Scale (ROP-Scale) with internal consistency measures and mean item score

\begin{tabular}{|c|c|c|c|c|}
\hline $\begin{array}{l}\text { Items (names slightly modified } \\
\text { from the original) }\end{array}$ & $\begin{array}{l}\text { Corrected } \\
\text { item-total } \\
\text { correlation }\end{array}$ & $\begin{array}{l}\text { Cronbach's alpha } \\
\text { coefficient for } \\
\text { domains }\end{array}$ & $\begin{array}{l}\text { Mean } \\
\text { item } \\
\text { score }\end{array}$ & $\begin{array}{l}\text { Median score } \\
\text { of the } \\
\text { domains }\end{array}$ \\
\hline \multicolumn{5}{|l|}{ Factor 1: Courteousness } \\
\hline 1. Greetings by doctor & 0.72 & \multirow[t]{4}{*}{0.87} & 7.75 & \multirow[t]{4}{*}{7.45} \\
\hline 2. Social talk & 0.63 & & 7.14 & \\
\hline $\begin{array}{l}\text { 3. Respect during the } \\
\text { consultation }\end{array}$ & 0.72 & & 8.16 & \\
\hline 4. Courage and reassurance & 0.71 & & 1.92 & \\
\hline \multicolumn{5}{|l|}{ Factor 2: Informativeness } \\
\hline $\begin{array}{l}\text { 5. Explanation about the } \\
\text { diagnosis }\end{array}$ & 0.67 & \multirow[t]{4}{*}{0.76} & 5.05 & \multirow[t]{4}{*}{6.45} \\
\hline $\begin{array}{l}\text { 6. Explanation about the } \\
\text { severity of the disease, } \\
\text { prognosis }\end{array}$ & 0.61 & & 5.98 & \\
\hline $\begin{array}{l}\text { 7. Explanation about } \\
\text { prevention, diet }\end{array}$ & 0.70 & & 6.92 & \\
\hline $\begin{array}{l}\text { 8. Facilitate post-treatment } \\
\text { follow-up }\end{array}$ & 0.64 & & 7.43 & \\
\hline \multicolumn{5}{|l|}{ Factor 3: Financial sensitivity } \\
\hline $\begin{array}{l}\text { 9. Understanding the socio- } \\
\text { economic condition of the } \\
\text { patient }\end{array}$ & 0.51 & \multirow[t]{2}{*}{0.95} & 1.92 & \multirow[t]{2}{*}{1.85} \\
\hline $\begin{array}{l}\text { 10. Providing treatment cost } \\
\text { estimate before starting } \\
\text { treatment }\end{array}$ & 0.52 & & 1.78 & \\
\hline \multicolumn{5}{|c|}{ Factor 5: Treatment provision sensitivity } \\
\hline $\begin{array}{l}\text { 11. Explanation about } \\
\text { the treatment }\end{array}$ & 0.37 & \multirow[t]{2}{*}{0.78} & 4.22 & \multirow[t]{2}{*}{4.07} \\
\hline $\begin{array}{l}\text { 12. Treatment using the sense } \\
\text { of humour }\end{array}$ & 0.54 & & 3.92 & \\
\hline
\end{tabular}

Responsiveness of physicians to hospitalised COVID-19 patients in Bangladesh: 
As can be seen from Table 4, the highest- and the lowest-scoring responsiveness domain are 'Courteousness' (median domain score 7.45), and 'Financial Sensitivity' (1.85). The two lowest-scoring items, 'Providing idea about treatment cost before starting treatment' (1.78), and 'Understanding the socio-economic condition of the patient' (1.92) belong to the Financial Sensitivity domain. 'Courage and reassurance' under 'Courteousness' domain also showed a low score (1.92). The two highest-scoring items were 'Respect during the consultation' (8.16) and 'Greetings by doctor' (7.75), both from the 'Courteousness' domain (Figure 2).

\section{Discussion}

\section{Statement of principal findings:}

As a part of our study, we validated the 12-item COVID-19 ROP-Scale with four domains, namely, Courteousness, Informativeness, Financial Sensitivity, and Treatment Provision Sensitivity. The scale was found to be feasible, valid, and internally consistent. The concurrent validity analyses further confirmed that higher responsiveness of physicians was associated with greater patient satisfaction. The Financial Sensitivity came out to be the lowest scoring of the COVID-19 ROP-Scale domains.

\section{Interpretation within the context of the wider literature:}

The main benefit of this scale stems from its feasibility, as it comprises of only 12 items, and it can be applied through exit interviews with the recent COVID-19 or similar infectious disease patients. While EFA is useful in psychometric studies for examining the dimensionality of the domains (18), the sample must be suitable for EFA, which according to Kaiser and Rice requires a statistically significant Bartlett's test and $\mathrm{a}>0.80 \mathrm{KMO}$ statistic. They also provided an evaluation criterion, according to which our sample was 'meritorious' to perform a satisfactory factor analysis (15). Internal consistency reliability of the COVID-19 ROP-Scale was ascertained through a reasonably high Cronbach's alpha coefficient and corrected itemtotal correlation, based on the 0.70 and 0.35 cut-off values, as recommended by Taber (19) and Netemeyer (20), respectively.

Criterion validity is the extent to which the scale score is associated with a relevant criterion variable external to the scale. One of the types of criterion validity is the concurrent validity, which is measured by assessing the correlation between the score of the scale under development and the concurrently collected criterion variable (20). In the present study, a correlation coefficient of $\geq 0.50$ was considered acceptable and was well surpassed by the COVID-19 ROP-Scale. The high Pearson's correlation coefficient (0.78) not only indicates a high concurrent validity, but also denotes the importance of responsiveness of physicians in achieving patient satisfaction, as shown by other authors $(1,16,17$, 21-24).

Empirical evidence further indicates that physicians in Bangladesh do not consider providing information on treatment cost as their responsibility, even though this is highly relevant to poor patients (1). Similar 
results were obtained in Lithuania, where the lack of financial sensitivity of the health service providers was reported by patients as one of the main reasons for their dissatisfaction with the healthcare provision (25). When the original ROP-Scale was administered in the rural-based outpatient setting in Bangladesh, 'Financial Sensitivity' was one of the lowest scoring domains (second lowest after the 'Friendliness' domain), and the lowest among the private sector physicians, likely due to the limited time for interacting with the patients. As the inpatient or hospital-based COVID-19 patients could receive greater attention from their healthcare providers, this would be reflected in a higher responsiveness score.

\section{Strengths and limitations:}

The main strength of this study is its conciseness and ease of completion, as all responses are required on a 10-point scale (rather than the 4-point Likert type scale used in the original ROP-Scale), which some patients may find more intuitive. This response format was also preferable as respondents could select a number without having to read the corresponding description, and it avoids potential skewedness caused by the range of response options chosen (e.g. 5- versus 6-point Likert scale) $(26,27)$.

The main limitation of this study is that the test-retest and inter-rater reliabilities of this scale were not evaluated. This decision was deliberate, as the study participants had recently recovered from COVID-19 at the time of the survey, and we did not deem it appropriate to engage them in yet another round of questioning. Secondly, the COVID-19 pandemic and the consequent lockdowns in Bangladesh also imposed time and resource constraints on the research team.

\section{Implications for policy, practice, and research:}

As the health system stewards attempt to improve the COVID-19 service delivery, they can use the present study findings to identify the gaps in service provision and develop a strategy for improving the responsiveness of physicians. This will not only enhance the service delivery but also increase patient satisfaction.

The data generated from this study and through future applications of the COVID-19 ROP-Scale can help determine and compare physician responsiveness in different geographic areas or healthcare settings, and among different patient populations, with the goal of addressing any identified gaps.

\section{Conclusion}

As demonstrated in this study, the revised ROP-Scale is valid and can be used in the context of COVID-19 pandemic or similar infectious disease outbreaks in Bangladesh or similar low-resource settings. This is particularly useful at a time when many countries, including Bangladesh, have started experiencing new waves of the pandemic. The COVID-19 ROP-Scale can help to amend past mistakes in health service provision, and improve care for the hospitalised COVID-19 patients or other patients suffering from similar conditions. This study can contribute to the national decision-making regarding hospital care, open up further avenues in the health policy and system research, and eventually improve the quality of care provided to all patients seeking hospital services in Bangladesh. Incorporating the learnings from 
this study, the medical education and in-service training for the doctors can be improved towards a more satisfied patient population.

\section{Abbreviations}

A2i - Aspire to Innovate

COVID-19 - Coronavirus Disease 2019

EFA - Exploratory Factor Analysis

EM - Expectation-maximisation

GoB - Government of Bangladesh

ICT - Information and Communication Technology

KMO - Kaiser-Meyer-Olkin

ROP - Responsiveness of Physicians

\section{Declarations}

\section{Ethics Approval and Consent to Participate:}

The study protocol is performed in accordance with the Declaration of Helsinki and approved by the Ethical Review Committee of the Public Health Foundation, Bangladesh (Reference number 04/2020). Since data were collected over the phone, a verbal informed consent was obtained from all the respondents. Verbal informed consent procedure was approved by the Ethical Review Committee of the Public Health Foundation, Bangladesh. All ethical principles were strictly adhered to. We ensured the confidentiality of the data.

\section{Consent for Publication:}

Not applicable.

\section{Availability of data and materials:}

The datasets used and/or analysed during the current study are available from the corresponding author on reasonable request.

\section{Competing Interests:}

The authors declare that they have no competing interests. 


\section{Funding:}

This was a self-funded research. The authors did not receive any fund for data collection, writing, publication or at any stage of the research from any organisation.

\section{Authors' Contributions:}

TJ conceptualized the study, designed the study, prepared data collection tools, critically revised and prepared the final manuscript. MAI prepared data collection tools, supervised data collection, drafted the manuscript and coordinated the whole project. MSI Prepared data collection tools, assisted in data analysis and drafted the manuscript. SM Collected the data and drafted the manuscript. MTH Curated and analyzed the data, prepared the results, and critically revised the manuscript. All authors read and approved the final manuscript.

Acknowledgements: The authors acknowledge the data collectors Apon Das, Marioum Akter Mou, and Jubair Mahmud. They worked hard to materialize this research in a resource-constrained situation. The authors also acknowledge the respondents, who recently recovered from the COVID-19, for their valuable time and information.

\section{References}

1. Joarder T, George A, Ahmed SM, Rashid SF, Sarker M. What constitutes responsiveness of physicians: A qualitative study in rural Bangladesh. PLoS One. 2017;12(12):e0189962.

2. Swift JK, Derthick AO. Increasing hope by addressing clients' outcome expectations. Psychotherapy. 2013;50(3):284.

3. Wittenberg E, Goldsmith JV, Chen C, Prince-Paul M, Johnson RR. Opportunities to improve COVID-19 provider communication resources: A systematic review. Patient Education and Counseling. 2021.

4. Rocque R, Leanza Y. A systematic review of patients' experiences in communicating with primary care physicians: intercultural encounters and a balance between vulnerability and integrity. PloS one. 2015;10(10):e0139577.

5. Maseko FC, Chirwa ML, Muula AS. Client satisfaction with cervical cancer screening in Malawi. BMC health services research. 2014;14(1):1-8.

6. Joarder T, Khaled MNB, Zaman S. Trust in the Bangladeshi Health System During the COVID-19 Pandemic: A Mixed-Methods Exploration. 2020.

7. Joarder T, Khaled MN, Joarder MA. Public perceptions of the COVID-19 pandemic management in Bangladesh: a qualitative exploration. F1000Research. 2021;10(170):170.

8. Joarder T, Mahmud I, Sarker M, George A, Rao KD. Development and validation of a structured observation scale to measure responsiveness of physicians in rural Bangladesh. BMC Health Services Research. 2017;17(1):753. 
9. Everitt BS. Multivariate analysis: The need for data, and other problems. The British Journal of Psychiatry. 1975;126(3):237-40.

10. Nunnally JC. Psychometric Theory: 2d Ed: McGraw-Hill; 1978.

11. Graham JW. Missing data analysis: Making it work in the real world. Annual review of psychology. 2009;60:549-76.

12. Thompson B. Exploratory and confirmatory factor analysis: Understanding concepts and applications. Washington DC: American Psychological Association; 2004.

13. Kaiser HF. The application of electronic computers to factor analysis. Educational and psychological measurement. 1960;20(1):141-51.

14. Stevens JP. Applied multivariate statistics for the social sciences: Routledge; 2012.

15. Kaiser HF, Rice J. Little jiffy, Mark IV. Educational and psychological measurement. 1974;34(1):111-7.

16. Hompashe DM, Gerdtham U-G, Christian CS, Smith A, Burger R. 'The nurse did not even greet me': how informed versus non-informed patients evaluate health systems responsiveness in South Africa. BMJ global health. 2021;6(4):e004360.

17. Onyeajam DJ, Xirasagar S, Khan MM, Hardin JW, Odutolu O. Antenatal care satisfaction in a developing country: a cross-sectional study from Nigeria. BMC Public Health. 2018;18(1):1-9.

18. DeVellis RF. Scale development: Theory and applications: Sage publications; 2016.

19. Taber KS. The Use of Cronbach's Alpha When Developing and Reporting Research Instruments in Science Education. Research in Science Education. 2018;48(6):1273-96.

20. Netemeyer RG, Bearden WO, Sharma S. Scaling procedures: Issues and applications: Sage Publications; 2003.

21. Aldana JM, Piechulek $\mathrm{H}$, Al-Sabir A. Client satisfaction and quality of health care in rural Bangladesh. Bulletin of the World Health Organization. 2001;79:512-7.

22. Cockcroft A, Andersson N, Milne D, Hossain MZ, Karim E. What did the public think of health services reform in Bangladesh? Three national community-based surveys 1999-2003. Health research policy and systems. 2007;5(1):1.

23. Andaleeb SS, Siddiqui N, Khandakar S. Patient satisfaction with health services in Bangladesh. Health policy and planning. 2007;22(4):263-73.

24. Trant AA, Szekely B, Mougalian SS, DiGiovanna MP, Sanft T, Hofstatter E, et al. The impact of communication style on patient satisfaction. Breast cancer research and treatment. 2019;176(2):349-56.

25. Bankauskaite V, Saarelma 0 . Why are people dissatisfied with medical care services in Lithuania? A qualitative study using responses to open-ended questions. International Journal for Quality in Health Care. 2003;15(1):23-029.

26. Ware JE, Hays RD. Methods for measuring patient satisfaction with specific medical encounters. Med Care. 1988;26(4):393-402. 

satisfaction scale. International Journal for Quality in Health Care. 2006;18(4):275-80.

\section{Figures}

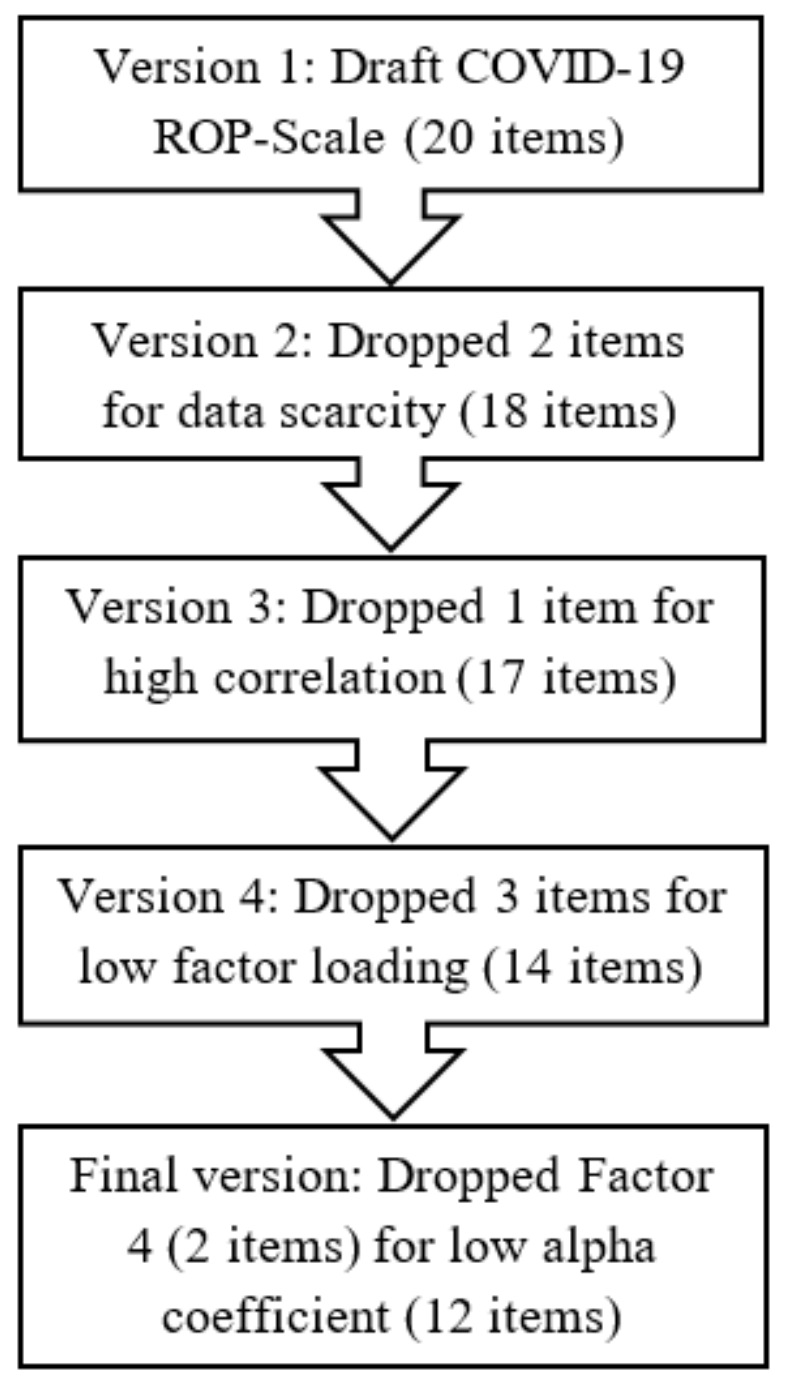

Figure 1

COVID-19 ROP-Scale validation process 


\section{Greetings by doctor}

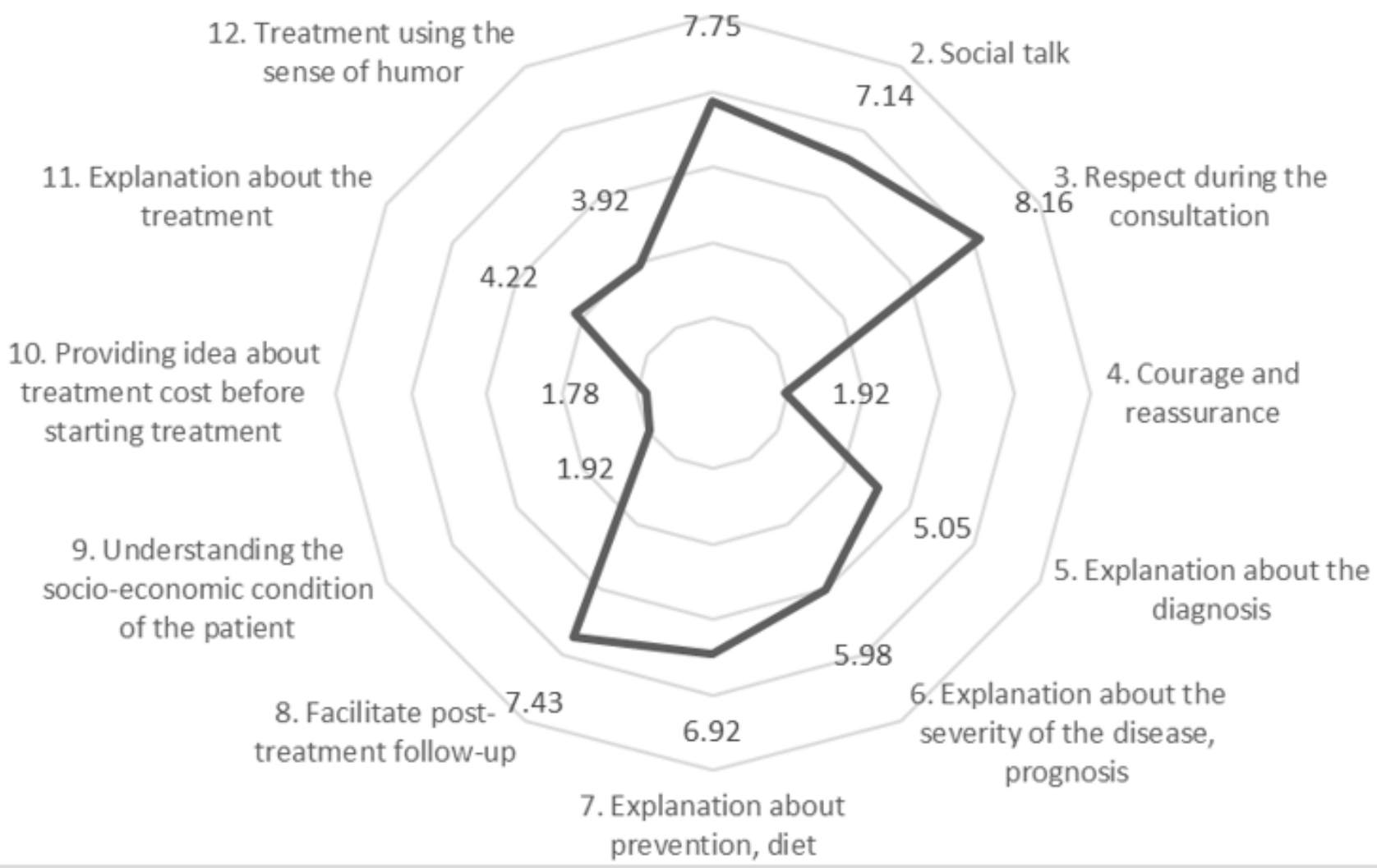

Figure 2

COVID-19 ROP-Scale scores 